\title{
BSA conjugates bearing multiple copies of the basic domain of HIV-1 Tat: Prototype for the development of multitarget inhibitors of extracellular Tat
}

\author{
Antonella Bugatti ${ }^{\mathrm{a}}$, Paola Chiodelli ${ }^{\mathrm{a}}$, Joseph Rosenbluh ${ }^{\mathrm{b}}$, Abraham Loyter ${ }^{\mathrm{b}}$, Marco Rusnati ${ }^{\mathrm{a}, *}$ \\ a Department of Biomedical Science and Biotechnology, School of Medicine, University of Brescia, 25123 Brescia, Italy \\ ${ }^{\mathrm{b}}$ Department of Biological Chemistry, The Alexander Silberman Institute of Life Sciences, The Hebrew University of Jerusalem, 91904 Jerusalem, Israel
}

\section{A R T I C L E I N F O}

\section{Article history:}

Received 20 November 2009

Received in revised form 2 March 2010

Accepted 6 April 2010

\section{Keywords:}

AIDS

HIV

Transactivation

Heparan sulfate proteoglycans

Integrins

Vascular endothelial growth factor receptor

Endothelial cells

Angiogenesis

\begin{abstract}
A B S T R A C T
The transactivating factor (Tat) of HIV-1 is involved in AIDS progression and associated pathologies Tat possesses a basic amino acid sequence implicated in heparan sulfate proteoglycan (HSPG)-mediated internalization, nuclear localization and transactivation by Tat and in the interaction of Tat with integrins and with the vascular endothelial growth factor receptor 2 (KDR) (kinase insert domain receptor). A BSA conjugate bearing an average of four copies of a peptide representing the basic domain/nuclear localization signal of Tat (BSA-Tat-NLS) inhibits transactivation by Tat exogenously added to cells but not by Tat endogenously produced after cell transfection with a tat cDNA, indicating that BSA-Tat-NLS does not interfere with Tat at an intracellular level. Surface plasmon resonance (SPR) experiments revealed that BSA-Tat-NLS binds to the HSPG analogue heparin. Accordingly, BSA-Tat-NLS binds to HSPGs of HL3T1 cell surface and inhibits HSPG-dependent Tat internalization. BSA-Tat-NLS retains its inhibitory potential when pre-incubated with HL3T1 cells before Tat administration, possibly by masking cell-surface HSPGs thus preventing Tat binding and internalization. SPR experiments revealed that BSA-Tat-NLS binds also to integrin $\alpha_{v} \beta_{3}$ and KDR. Accordingly, it inhibits pro-angiogenic endothelial cell adhesion to Tat and motogenesis. In conclusion, BSA-Tat-NLS binds/masks three different cell-surface receptors of Tat inhibiting different biological activities. These data point to BSA-Tat-NLS as a prototype for the development of Tat-antagonists endowed with a multitargeted mechanism of action.
\end{abstract}

(C) 2010 Elsevier B.V. All rights reserved.

\section{Introduction}

HIV-1 Tat is a transcriptional activator of the viral long terminal repeat (LTR) promoter that is essential for viral replication (Dayton et al., 1986; Fisher et al., 1986). Tat is a polypeptide of 86-102 amino acids, depending on the viral strain, which is encoded by two exons and is translated from multiply spliced 2-kilobase mRNAs (Schwartz et al., 1990). In HIV+ cells, Tat must be actively translocated to the nucleus to exert its transactivating function (Cullen, 1995). Usually, translocation of molecules to the nucleus occurs via the nuclear pore complex and is governed by cellular proteins known as importins (Kim et al., 1992). The interaction between importins and target proteins is mediated by nuclear localization signals (NLSs) present in the latter. NLSs are short amino acid stretches usually containing positively charged residues such as Lys and $\operatorname{Arg}$ (Jans et al., 2000). Within the sequence encoded by the first exon of tat is present an amino acid sequence (49-57) (also known

\footnotetext{
* Corresponding author at: General Pathology \& Immunology, Department of Biomedical Sciences and Biotechnology, viale Europa 11, 25123 Brescia, Italy. Tel: +39 0303717315 ; fax: +390303701157.

E-mail address: rusnati@med.unibs.it (M. Rusnati).
}

as the basic domain of Tat) constituted by a stretch of repeated Arg and Lys residues that is highly immunoreactive and well conserved among Tat isolated from different HIV-1 strains (Goldstein, 1996). This basic domain plays different roles in the intracellular fate of Tat: it acts as an effective Tat NLS, able to mediate nuclear import of large cargoes (Efthymiadis et al., 1998; Gautier et al., 2005). Also, it is necessary for Tat stability inside the cell and for Tat interaction with the transactivation responsive region (TAR) RNA (Watson and Edwards, 1999).

Although originally discovered as an intracellular transactivator, Tat can be released by HIV+ cells (Ensoli et al., 1993). Extracellular Tat enters latently HIV+ cells and activates the transcription of the viral genome (Mann and Frankel, 1991). In AIDS patients, HIV reactivation by extracellular Tat may explain the "burst" of replication associated with early phases of HIV infection, where synchronized virion replication takes place (Peterlin et al., 1993). Extracellular Tat uptake by cells occurs via the interaction of cell-surface heparan sulfate proteoglycans (HSPGs) with the basic domain/NLS of Tat (Rusnati et al., 1998; Futaki et al., 2001). Accordingly, this sequence has been exploited as an effective protein transduction domain to mediate cell internalization of a variety of molecules (Fittipaldi and Giacca, 2005; Chauhan et al., 2007). Extracellular Tat can act also as a cytokine, targeting HIV-non permissive cells [including endothe- 
Table 1

Peptides used in this study.

\begin{tabular}{lll}
\hline Peptide & Sequence & Derived from \\
\hline SV40-NLS & PKKKRKV $^{*}$ & SV40 T-antigen \\
SV40 reverse (rev) & VKRKKKP $^{*}$ & HIV-1 transcription \\
Tat-NLS & GRKKRRQRRRAHQN & activation protein \\
p53 & KALGISYGRKKRRQRRRAH & tumor suppressor \\
\hline
\end{tabular}

Peptides derived from SV40 and Tat act as nuclear localization signal (Hodel et al., 2001; Gautier et al., 2005). The peptide derived from p53 acts as nuclear export signal (Liang and Clarke, 2001). ${ }^{*}$ Peptides fused to BSA on the average of 4 copies/BSA monomer (Friedler et al., 1999).

lial cells (ECs) (Rusnati and Presta, 2002a)], and inducing a variety of biological effects that contribute to the pathogenesis of AIDSassociated pathologies (Rusnati and Presta, 2002a). Tat exerts these effects by interacting with different cell-surface receptors including integrins (Urbinati et al., 2005a), the vascular endothelial growth factor receptor 2 (KDR) (kinase insert domain receptor) (Albini et al., 1996b) and the chemokine receptors CXCR4 and CCL5 (Albini et al., 1998). Interestingly, the interaction of Tat with integrins and KDR occurs, at least in part, through the basic domain/NLS of Tat (Rusnati et al., 2001b; Urbinati et al., 2005a), as already seen for HSPGs. At variance, the interaction of Tat with chemokine receptors occurs through its cystein-rich domain (amino acid sequence 24-51) (Albini et al., 1998).

In conclusion, by acting with both intra- and extracellular mechanisms of action, Tat plays crucial roles in HIV replication and in the pathogenesis of AIDS-associated diseases, Tat being considered as a pivotal target for the development of anti-AIDS therapies. Accordingly, numerous intra- (Richter and Palù, 2006) and extracellular (Rusnati et al., 2005) inhibitors of Tat have been developed. In this scenario, the basic domain/NLS of Tat emerges as a pivotal molecular target because of its involvement in many important aspects of Tat biology both inside and outside the cell.

Conjugation of synthetic peptides to carriers such as bovine serum albumin (BSA) leads to multivalent complexes that increase almost a thousand fold the binding affinity of the peptides for their natural ligands (Goldfarb et al., 1986). In effect, NLSs have been successfully conjugated to BSA to produce complexes that retain nuclear localization capacity (Goldfarb et al., 1986; Hariton-Gazal et al., 2003; Armon-Omer et al., 2004). Accordingly, BSA bearing covalently attached peptides representing the basic domain/NLS of Tat acts as a nuclear import vehicle in permeabilized cells (Krichevsky et al., 2005).

On these bases, we decided to evaluate the capacity of Tat-NLS, before or after its fusion to BSA in multiple copies (BSA-Tat-NLS), to interfere with the intra- and extracellular activity of Tat. The aim was to validate the use of this class of compounds as a prototype for the development of Tat-antagonists endowed with a multitargeted mechanism of action.

\section{Materials and methods}

\subsection{Reagents}

86 amino acid HIV-1 Tat was expressed and purified by Escherichia coli as glutathione-S-transferase (GST-Tat) or GST-Tatgreen fluorescent protein (GST-Tat-GFP) fusion proteins (Rusnati et al., 1998, 2000). To avoid Tat oxidation, purified proteins were maintained at $-20^{\circ} \mathrm{C}$ in Tris $100 \mathrm{mM}$ pH 9.5 containing $250 \mathrm{mM}$ $\mathrm{NaCl}, 20 \mathrm{mM}$ glutathione and $5 \mathrm{mM}$ dithiothreitol. GST and GFP moieties do not interfere with Tat internalization nor with its heparin-binding, transactivating and cell-adhesive capacity (Tyagi et al., 2001). The synthetic peptide representing the amino acid sequence 41-60 of Tat (Table 1 ) was from MRC AIDS Reagent Project (Potters Bar, Herts, UK). The synthetic peptides used as fusion pro- teins with BSA (Table 1) were from GL-Biochem (China). Heparin (13.6 kDa) was from Laboratori Derivati Organici Spa (Milan, Italy). The soluble form of recombinant human KDR was from RELIAtech (Lindenerstr, Germany). Biotinylated BSA (bBSA), fibronectin (FN) and heparinase II were from Sigma (St. Louis, MO). Purified integrin $\alpha_{v} \beta_{3}$ was from Chemicon International-Inc. (Temecula, CA). Biotinylated Tat (bTat) was from Tecnogen (Caserta, Italy). SU5416 (an inhibitor of the tyrosine kinase activity of KDR) was from Calbiochem (La Jolla, CA).

\subsection{Synthesis of BSA conjugates containing multiple copies of NLSS}

A cysteine residue was added to the $C$ termini of the peptides to allow conjugation to BSA through the maleimide group of the sulfosuccinimidyl 4-(N-maleimidomethyl)cyclohexan-1-carboxylate. The peptides were then conjugated to unlabelled BSA or to bBSA as described (Broder et al., 1997), allowing the fusion on the average of 4 molecules of peptide for each BSA monomer (Friedler et al., 1999).

\subsection{Surface plasmon resonance (SPR) equipment and reagents}

SPR measurements were performed on a BIAcore $\mathrm{X}$ instrument (GE-Healthcare, Milwaukee, WI). The reagents 1-ethyl3-(3-diaminopropyl)-carbodiimide hydrocloride (EDC) and $\mathrm{N}$ hydroxysuccinimide (NHS) were purchased from GE-Healthcare and used according to recommended protocols.

For the study of BSA conjugates/heparin interaction, heparin was immobilized to a BIAcore sensorchip (Rusnati et al., 2001a). Briefly, a CM3 sensorchip activated with $50 \mu$ l of a mixture containing $0.2 \mathrm{M}$ EDC and $0.5 \mathrm{M}$ NHS was coated with streptavidin. Heparin was biotinylated at its reducing end and immobilized onto the streptavidin-coated sensorchip, allowing the immobilization of 80 resonance units (RU) $\left(5.8 \mathrm{fmol} / \mathrm{mm}^{2}\right.$ of heparin). A sensorchip coated with streptavidin alone was used as a reference and for blank subtraction. The various BSA conjugates in $10 \mathrm{mM}$ HEPES pH 7.4 containing $150 \mathrm{mM} \mathrm{NaCl}, 3$ mM EDTA, 0.005\% surfactant P20 (HBS-EP) were injected over the heparin or streptavidin surfaces for 4 min (to allow their association with immobilized molecules) and then washed until dissociation was observed. After every run, the sensorchip was regenerated by injection of $2.0 \mathrm{M} \mathrm{NaCl}$ in HBS-EP.

For the study of BSA-Tat-NLS $/ \alpha_{\mathrm{v}} \beta_{3}$ interaction, an experimental model already set up was used (Urbinati et al., 2005a). Briefly, $50 \mu \mathrm{g} / \mathrm{ml}$ of BSA-Tat-NLS were allowed to react with a CM5 sensorchip activated as described above, leading to the immobilization of $10,200 \mathrm{RU}$ ( 0.3 pmoles $/ \mathrm{mm}^{2}$ of BSA-Tat-NLS). Similar results were obtained for the immobilization of BSA, used as a negative control and for blank subtraction. Integrin $\alpha_{v} \beta_{3}$ in $10 \mathrm{mM}$ HBS-EP was then injected over the BSA-Tat-NLS or BSA surfaces for 4 min and then washed until dissociation. After every run, the sensorchip was regenerated by injection of $2.0 \mathrm{M} \mathrm{NaCl}$ in HBS-EP.

For the study of BSA conjugates/KDR interaction, recombinant $\mathrm{KDR}(20 \mu \mathrm{g} / \mathrm{ml}$ in $10 \mathrm{mM}$ sodium acetate buffer $\mathrm{pH}$ 5.3) was allowed to react with a flow cell of a CM5 sensorchip activated as described above, allowing the immobilization of $6900 \mathrm{RU}\left(0.06 \mathrm{pmoles} / \mathrm{mm}^{2}\right.$ of KDR). Similar results were obtained for the immobilization of gelatin, used as a negative control and for blank subtraction. The various BSA conjugates in $10 \mathrm{mM}$ HBS-EP were injected over the KDR or gelatin surfaces for $4 \mathrm{~min}$ and then washed until dissociation. After every run, the sensorchip was regenerated by injection of HBS-EP containing $2.0 \mathrm{M} \mathrm{NaCl}$ followed by a pulse of $5 \mu \mathrm{l}$ of HBS-EP containing $0.02 \%$ SDS.

Binding parameters were calculated by the non-linear curve fitting software package BIAevaluation 3.2 using a single site model with a drifting baseline. 


\subsection{Cell cultures}

HL3T1 cells, derived from HeLa cells, contain integrated copies of pL3CAT plasmid in which the chloramphenicol acetyltransferase (CAT) bacterial gene is driven by HIV-1 LTR (Wright et al., 1986). HL3T1 cells were maintained in DMEM (Gibco, Grand Island, NY) supplemented with $10 \%$ FCS, $100 \mathrm{U} / \mathrm{ml}$ penicillin and $100 \mathrm{U} / \mathrm{ml}$ streptomycin (Broder et al., 1997). Transformed fetal bovine aortic endothelial GM7373 cells (Grinspan et al., 1983) were grown in DMEM supplemented with $10 \%$ FCS.

\subsection{Cell-binding assay of biotinylated proteins}

Monolayer of HL3T1 cells in 96-well plates was incubated for $2 \mathrm{~h}$ at $4{ }^{\circ} \mathrm{C}$ with increasing concentrations of biotinylated proteins in phosphate-buffered saline (PBS) containing $0.1 \mathrm{mg} / \mathrm{ml} \mathrm{CaCl}_{2}$, $0.1 \mathrm{mg} / \mathrm{ml} \mathrm{MgCl} 2,0.1 \%$ gelatin. In some experiments, HL3T1 cell monolayers were incubated for $90 \mathrm{~min}$ at $37^{\circ} \mathrm{C}$ with PBS containing heparinase II $(1.5 \mathrm{mU} / \mathrm{ml})$ before the binding assays. After PBS washing, the amount of cell associated biotinylated proteins was determined with horseradish peroxidase-labeled streptavidin (1/5000) and the chromogen substrate ABTS (Kierkegaard \& Perry Laboratories, Gaithersburg, MD).

\subsection{Internalization of GST-Tat-GFP}

HL3T1 cells adherent to glass coverslips were incubated for $6 \mathrm{~h}$ at $37{ }^{\circ} \mathrm{C}$ in DMEM containing $10 \%$ FCS, $100 \mu \mathrm{M}$ chloroquine (Frankel and Pabo, 1988) and GST-Tat-GFP (6nM) in the presence of the various BSA conjugates. Then, cells were washed with PBS containing $\mathrm{NaCl}$ at a final concentration equal to $2.0 \mathrm{M}(\mathrm{PBS} / 2 \mathrm{M} \mathrm{NaCl})$ to remove cell-surface-bound GST-Tat-GFP and fixed. Observations were carried out under a Zeiss Axiovert $200 \mathrm{M}$ microscope equipped for fluorescence analysis and connected to a Hal 100 digital camera (Carl Zeiss, Jena, Germany) (Rusnati et al., 1999).

\subsection{HIV-1 LTR transactivation assay}

HL3T1 cells were incubated for $24 \mathrm{~h}$ in DMEM containing $10 \%$ FCS, $100 \mu \mathrm{M}$ chloroquine (Frankel and Pabo, 1988), and GST-Tat $(6 \mathrm{nM})$ in the presence of the various BSA conjugates. Conditioned medium was removed and cells further incubated for $24 \mathrm{~h}$ in DMEM containing $10 \%$ FCS. Then, the amount of CAT protein present in the cell extracts was determined using a CAT ELISA kit (Boehringer, Mannheim, Germany) (Rusnati et al., 1997a).

\subsection{Cell adhesion assay}

Aliquots $(100 \mu \mathrm{l})$ of $100 \mathrm{mM} \mathrm{NaHCO}_{3} \mathrm{pH} 9.6$ containing GST-Tat or FN $(20 \mu \mathrm{g} / \mathrm{ml})$ were incubated onto 96 -wells polystyrene nontissue culture plates for $16 \mathrm{~h}$ at $4{ }^{\circ} \mathrm{C}$. Then, the solution was removed and the wells washed with PBS. GM7373 cells (50,000/200 $\mu \mathrm{l})$ were directly seeded onto coated wells or mixed for $2 \mathrm{~h}$ at $4{ }^{\circ} \mathrm{C}$ with the various BSA conjugates or with the HSPG-antagonist heparin before seeding. After $2 \mathrm{~h}$ of incubation at $37^{\circ} \mathrm{C}$, wells were washed with 2 mM EDTA in PBS and DMEM without serum. Adherent cells were then trypsinized and counted in a Burker chamber (Rusnati et al., 1997b).

\subsection{EC monolayer scratching assay}

Monolayers of GM7373 cells adherent to GST-Tat were scratched and incubated at $37^{\circ} \mathrm{C}$ with DMEM containing $0.4 \% \mathrm{FCS}$ in the presence of the HSPG-antagonist heparin, of the KDR inhibitor SU5416 or of the various BSA conjugates. Photomicrographs were taken under an inverted microscope (Olympus $1 \times 51$ microscope with a Camedia C-4040 digital camera, $\times 10 / 0.25$; Olympus Biosystem, Munich, Germany). The area of the scratch was evaluated by computerized image analysis using the Image Pro-Plus analysis system (Urbinati et al., 2005a).

\section{Results}

\subsection{BSA-Tat-NLS binds to heparin/HSPGs and inhibits Tat internalization and transactivating activity}

The basic domain/NLS of Tat is necessary for the uptake of the protein, its nuclear translocation, its interaction with TAR RNA and its transactivating activity. On these bases, we decided to evaluate the effect of synthetic peptides representing the basic domain/NLS of Tat (Tat-NLS) on Tat-driven LTR-transactivation in HL3T1 cells.

In a first series of experiments, we compared the Tat-antagonist potential of these peptides before or after their conjugation to BSA in multiple copies, a procedure that usually increases the affinity of conjugated peptides for their natural ligands (Goldfarb et al., 1986). As shown in Fig. 1A, the synthetic peptide representing the basic domain/NLS of Tat per se does not inhibit the LTR-transactivation induced by GST-Tat in HL3T1 cells when assayed at doses up to $4 \mu \mathrm{M}$. On the contrary, the BSA-Tat-NLS conjugate, containing up to 4 peptides for each BSA monomer (Friedler et al., 1999), inhibits Tat-driven transactivation in a dose-dependent way. The inhibition is specific since the other BSA conjugates tested are ineffective. As expected, heparin, a polyanionic Tat-antagonist that sequesters the transactivating factor in the extracellular environment (Rusnati et al., 1997a), inhibits Tat transactivating activity. These data indicate that a peptide representing the basic domain/NLS of Tat does not inhibit the transactivating activity of HIV-1 Tat, unless it is fused in multiple copies to a carrier as BSA.

As mentioned in the Introduction, the basic domain/NLS of Tat drives its nuclear translocation and interaction with TAR RNA. To determine whether BSA-Tat-NLS inhibits Tat transactivating activity by interfering with these intracellular processes, HL3T1 cells were transiently transfected with an expression vector harboring the HIV-1 tat cDNA, obtaining an intracellular overexpression of Tat. This experimental model has been already used to bypass the process of extracellular Tat internalization (Tyagi et al., 2001) and to discriminate between intra- or extracellular inhibitors of Tat (Rizzi et al., 2004). As shown in Fig. 1B, LTR transactivation driven by intracellular Tat is not affected by exogenously added BSA-Tat-NLS. Noticeably, this lack of inhibition is maintained in the presence of sub-optimal levels of LTR transactivation (obtained by performing cell transfection with tat cDNA at $0.25 \mu \mathrm{g} / \mathrm{ml}$ or by adding exogenous GST-Tat at $6 \mathrm{nM}$ ). Also, raising the amount of exogenous GST-Tat added to cells, an increase of LTR-transactivation is obtained that remains, however, inhibited by BSA-Tat-NLS. Thus, the inability of BSA-Tat-NLS to interfere with intracellular Tat is not merely due to the presence of an excess of intracellular protein driven by tat cDNA tranfection.

To further investigate the mechanism of inhibition, BSA-TatNLS was administered to HL3T1 cells together with GST-Tat or at different times after GST-Tat administration. As shown in Fig. 1C, BSA-Tat-NLS inhibits the LTR-transactivating activity of Tat when added $1 \mathrm{~h}$ after the administration of GST-Tat, while its addition $3 \mathrm{~h}$ after the beginning of GST-Tat treatment was ineffective. In these experimental conditions, the extracellular Tat-antagonist heparin (Rusnati et al., 1997a) behaves exactly as BSA-Tat-NLS. Relevant to this point, a 3-h incubation allows the internalization of an amount of Tat that is sufficient to exert an optimal LTR-transactivation (Tyagi et al., 2001) and that becomes inaccessible to extracellular inhibitors remaining, however, sensible to intracellular inhibitors (Rizzi et al., 2004). 

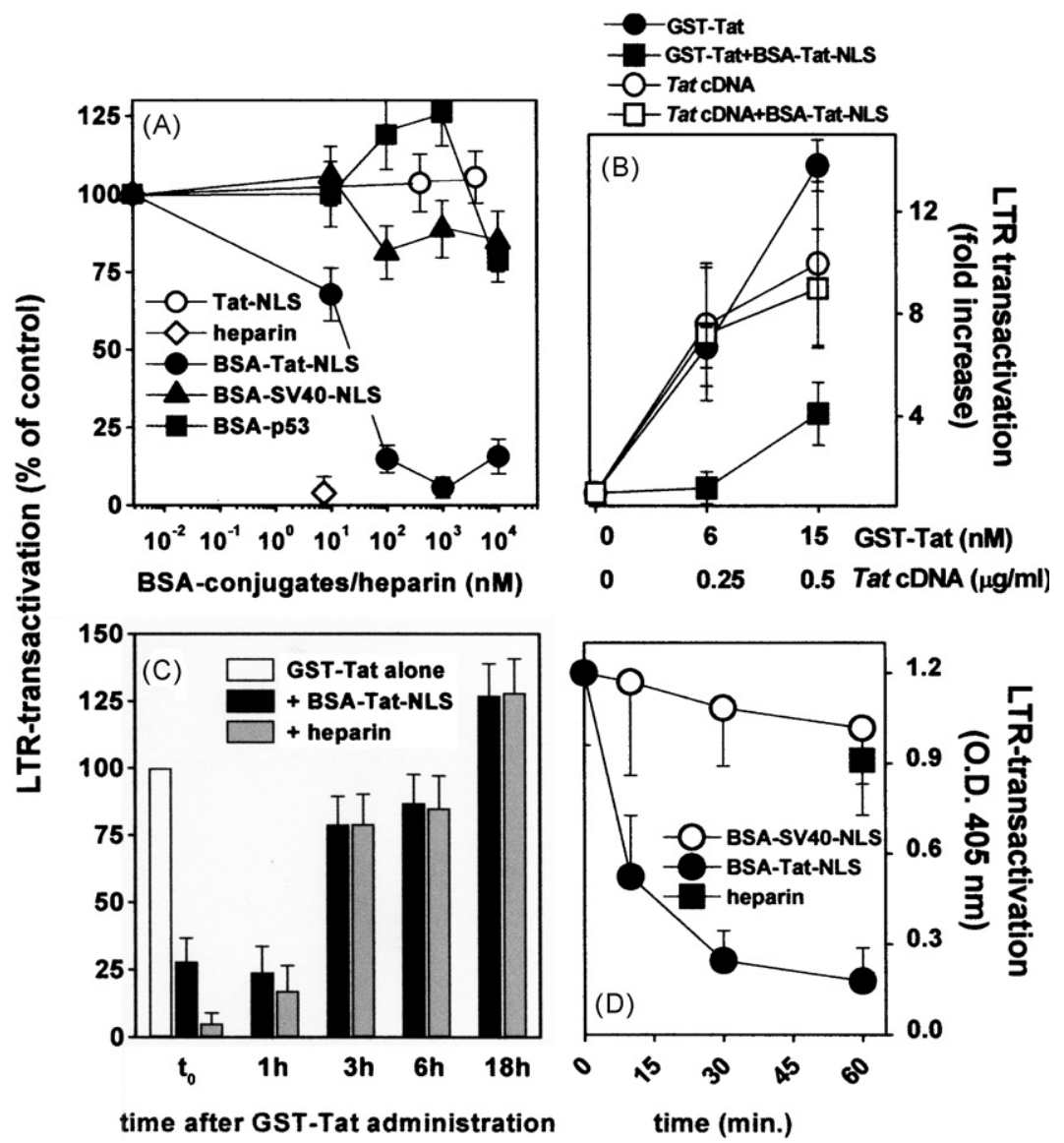

Fig. 1. Effect of BSA-Tat-NLS on Tat transactivating activity.

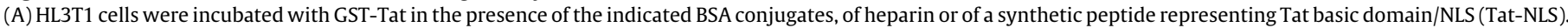

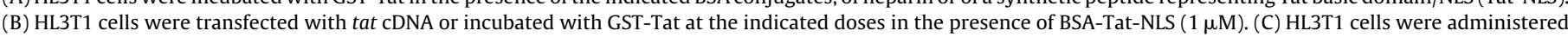

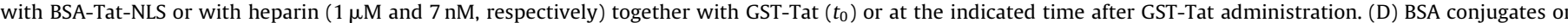

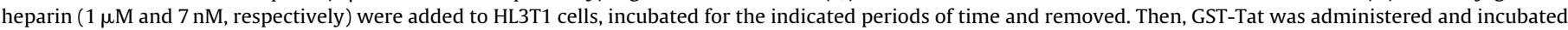
for further $18 \mathrm{~h}$ at $37^{\circ} \mathrm{C}$. At the end of incubations, cell extracts were assayed for the CAT levels. Each point is the mean \pm S.E.M. of 3-6 duplicate determinations.

Taken together, these data sustain the hypothesis that BSATat-NLS exerts its inhibition acting extracellularly, being unable to block Tat once this is penetrated inside the cell in bioactive amounts.

In parallel experiments, BSA-Tat-NLS was allowed to react with the surface of HL3T1 cells and the excess of free conjugate removed. Then, HL3T1 cells were assayed for their responsiveness to Tat. As shown in Fig. 1D, very short pre-incubation of HL3T1 cells with BSA-Tat-NLS causes a loss of cell responsiveness to Tat. The effect is specific since HL3T1 cells pre-incubated with BSA-SV40-NLS retain their capacity to transactivate in response to Tat. Heparin [that sequesters Tat extracellularly (Rusnati et al., 1997a)] is ineffective when added to cells in the absence of the transactivating factor. Taken together, these data indicate that BSA-Tat-NLS exerts its inhibition by interfering with an early event (most likely cell-surface interaction/internalization of extracellular Tat) without the necessity to physically interact with the transactivating factor.

The basic domain/NLS of Tat mediates the interaction of extracellular Tat with cell surface HSPGs (Rusnati et al., 1998) that, in turn, is necessary for Tat internalization and transactivating activity (Tyagi et al., 2001). We then investigated if BSA-Tat-NLS exerts its inhibition by binding to cell-surface HSPGs, hampering their interaction with Tat and thus inhibiting Tat internalization. To this purpose, we firstly evaluated the capacity of BSA-Tat-NLS to bind heparin (a structural analogue of HSPGs) immobilized on a BIAcore sensorchip, a "cell-free" model that resembles Tat interaction with cell-surface HSPGs (Rusnati et al., 2001a). BSA-Tat-NLS, but not the other BSA conjugates tested, binds to the heparin surface (Fig. 2A). The binding is dose-dependent (Fig. 2B) and occurs with parameters (Table 2) that are comparable to those calculated for the intact Tat protein (Rusnati et al., 2001a).

Given the capacity of BSA-Tat-NLS and intact Tat to bind to surface-immobilized heparin, we compared their capacity to bind to HSPGs expressed at the surface of HL3T1 cells. As shown in Fig. 2, bTat and bBSA-Tat-NLS, but not bBSA-SV40-NLS, binds to HL3T1 cells. The different O.D. values measured for bBSA-Tat-NLS and intact bTat at saturation (0.07 and 0.2 , respectively) likely account for the presence of one biotin for each BSA monomer bearing four copies of the Tat-NLS versus one biotin for each intact Tat protein (Fig. 2C and D). bBSA-Tat-NLS binds HL3T1 cells in a dose-dependent way with an $\mathrm{ED}_{50}$ equal to $4.5 \mathrm{nM}$ (Fig. $2 \mathrm{C}$ ). This

Table 2

Binding parameters of the interactions of BSA-NLS conjugates to heparin immobilized to a BIAcore sensorchip.

\begin{tabular}{llll}
\hline Conjugate & $\begin{array}{l}\text { Association } \\
\text { rate }(1 / \mathrm{Ms})\end{array}$ & $\begin{array}{l}\text { Dissociation } \\
\text { rate }(1 / \mathrm{s})\end{array}$ & $\begin{array}{l}\text { Dissociation } \\
\text { constant }(\mathrm{M})\end{array}$ \\
\hline BSA-Tat-NLS & $1.45 \times 10^{5}$ & $8.01 \times 10^{-4}$ & $1.57 \times 10^{-9}$ \\
BSA-SV40-NLS & n.d. & n.d. & n.d. \\
BSA-SV40 rev-NLS & n.d. & n.d. & n.d. \\
BSA-p53 & n.d. & n.d. & n.d. \\
GST-Tat & $1.0 \times 10^{6}$ & $1.68 \times 10^{-3}$ & $5.53 \times 10^{-9}$ \\
\hline
\end{tabular}

The results shown are representative of other two that gave similar results. n.d.: not determinable. 

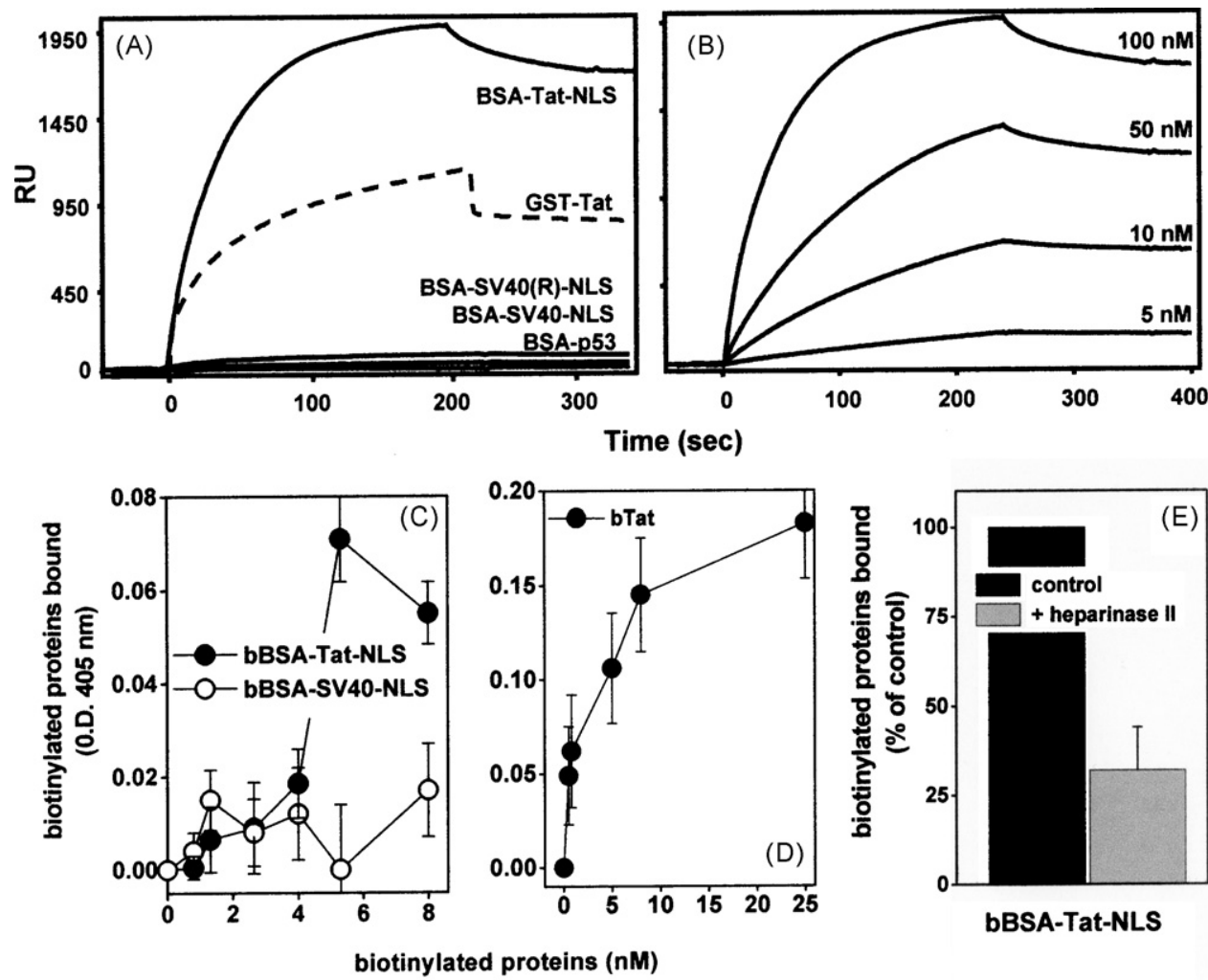

Fig. 2. Binding of BSA-Tat-NLS to heparin and to HL3T1 cell surface.

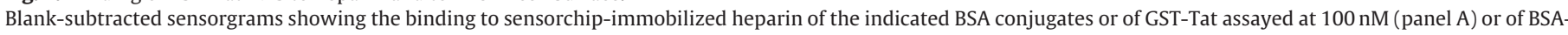

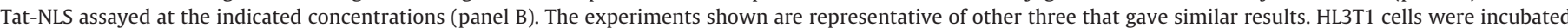

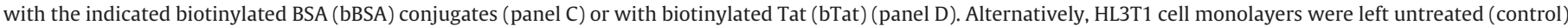

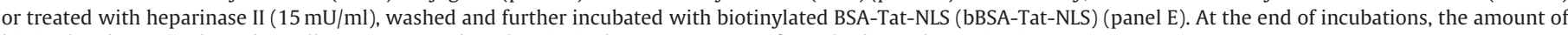
biotinylated proteins bound to cells was measured. Each point is the mean \pm S.E.M. of 3-5 duplicate determinations.

value is comparable to that calculated for the binding of bTat $\left(\mathrm{ED}_{50}\right.$ equal to $4.9 \mathrm{nM}$, Fig. 2D) and to the dissociation constant $\left(K_{\mathrm{d}}\right)$ calculated for BSA-Tat-NLS/heparin interaction in the BIAcore model (Table 2). Taken together, these data suggest that the binding of BSA-Tat-NLS to HL3T1 cell-surface occurs via HSPGs. To formally demonstrate this possibility, HL3T1 cells were treated with heparinase II, a glycosidase that removes HSPGs from the surface of different cell types (Urbinati et al., 2009), and then evaluated for their capacity to bind to bBSA-Tat-NLS. As shown in Fig. 2E, heparinase II-treatment causes a significant reduction of the capacity of HL3T1 cells to bind bBSA-Tat-NLS, thus demonstrating that this interaction mainly occurs via cell-surface HSPGs, as already demonstrated for intact Tat protein (Albini et al., 1996a). Interestingly, HSPG depletion by heparinases has been demonstrated to inhibit also Tat internalization in HL3T1 cells (Tyagi et al., 2001). Taken together, these data suggest that BSA-Tat-NLS competes with extracellular Tat for the binding to cell-surface HSPGs preventing Tat internalization and transactivation.

Tat is rapidly internalized by HL3T1 cells in a HSPG-dependent way (Tyagi et al., 2001). Two hours after its addition, it is found
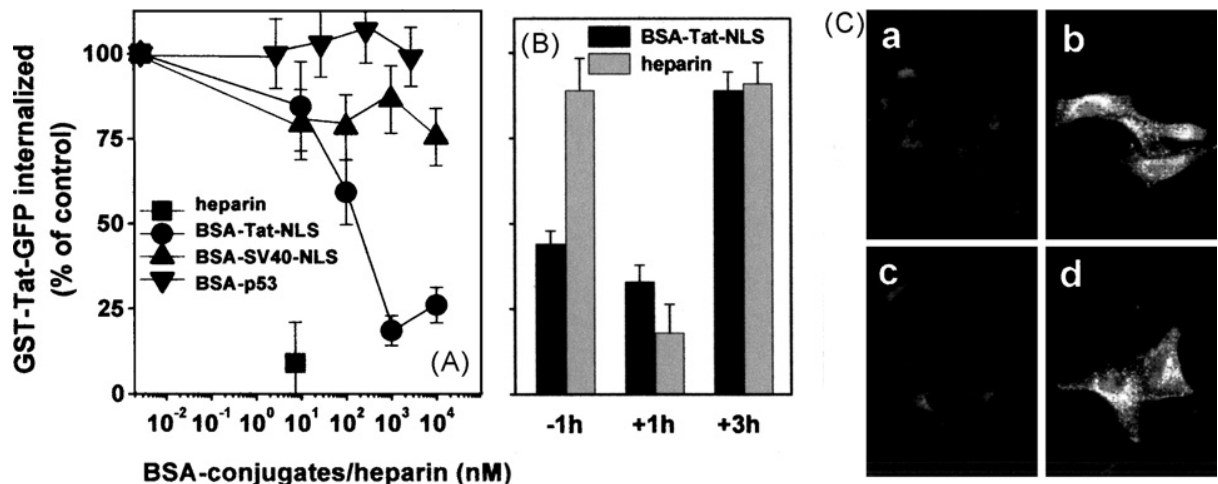

Fig. 3. Effect of BSA-Tat-NLS on Tat internalization.

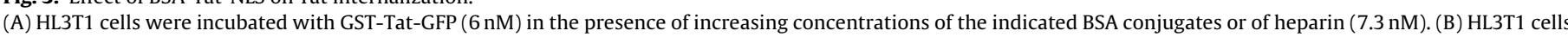

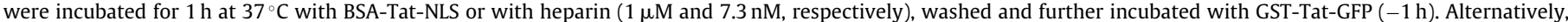

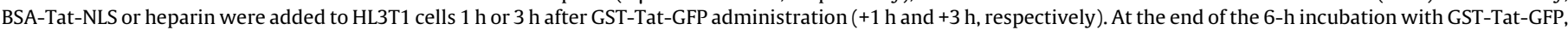

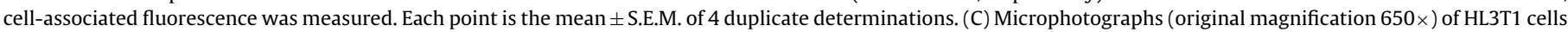
treated without (a) or with GST-Tat-GFP alone $(6 \mathrm{nM})(\mathrm{b})$ or in the presence of BSA-Tat-NLS (c) or of BSA-SV40-NLS (d) $(1 \mu \mathrm{M})$. 
Table 3

Binding parameters of the interactions of BSA-NLS conjugate and GST-Tat to integrin $\alpha_{\mathrm{v}} \beta_{3}$ and KDR.

\begin{tabular}{|c|c|c|c|c|}
\hline Receptor & Ligand & Association rate (1/Ms) & Dissociation rate $(1 / \mathrm{s})$ & Dissociation constant (M) \\
\hline \multirow{2}{*}{ Integrin $\alpha_{V} \beta_{3}$} & BSA-Tat-NLS & $1.66 \times 10^{8}$ & $9.48 \times 10^{-3}$ & $6,03 \times 10^{-9}$ \\
\hline & ${ }^{*}$ GST-Tat & $1.16 \times 10^{7}$ & $3.78 \times 10^{-1}$ & $3,2 \times 10^{-8}$ \\
\hline \multirow{4}{*}{ KDR } & BSA-Tat-NLS & $1.3 \times 10^{4}$ & $2.1 \times 10^{-3}$ & $1.72 \times 10^{-7}$ \\
\hline & BSA-SV40-NLS & n.d. & n.d. & n.d. \\
\hline & BSA-p53 & n.d. & n.d. & n.d. \\
\hline & GST-Tat & $1.74 \times 10^{5}$ & $1.16 \times 10^{-5}$ & $6,68 \times 10^{-11}$ \\
\hline
\end{tabular}

The results shown are representative of other two that gave similar results. n.d.: not determinable, ${ }^{*}$ data from (Urbinati et al., $\left.2005 a\right)$.

inside endosomal vesicles (Mann and Frankel, 1991; Tyagi et al., 2001). At $4 \mathrm{~h}$, it reaches significant intracellular levels and is found in the nucleus (Tyagi et al., 2001). To directly demonstrate the capacity of BSA-Tat-NLS to inhibit Tat internalization, GST-Tat-GFP was administered to HL3T1 cells in the absence or in the presence of BSA-Tat-NLS. As shown in Fig. 3A, BSA-Tat-NLS inhibits in a dose-dependent way the internalization of GST-Tat-GFP in HL3T1 cells. The inhibition is specific since the other BSA conjugates tested are ineffective. Also, a 1-h pre-incubation of cells with BSA-Tat-NLS (Fig. 3B), but not with BSA-SV40-NLS or BSA-p53 (data not shown), inhibits the capacity of HL3T1 cells to internalize GSTTat-GFP. Heparin inhibits Tat internalization only when incubated together with the transactivating factor [allowing the formation of inactive heparin/Tat complexes in the extracellular environment (Rusnati et al., 1997a)], while it is ineffective when pre-incubated with the cells in the absence of Tat (Fig. 3B). Finally, both BSA-TatNLS and heparin retain their capacity to inhibit Tat internalization if added $1 \mathrm{~h}$, but not $3 \mathrm{~h}$ after Tat administration (Fig. 3B). Noticeably, the different capacity displayed by BSA-Tat-NLS and heparin to inhibit Tat-internalization correlate with their capacity to inhibit Tat-driven transactivation (see Fig. 1).

In conclusion, BSA-Tat-NLS acts as an extracellular Tatantagonist that prevents HSPG-dependent internalization of Tat, likely by binding and masking HSPGs to the transactivating factor.

\subsection{BSA-Tat-NLS binds integrin $\alpha_{v} \beta_{3}$ and KDR and inhibits the pro-angiogenic activity of Tat}

As mentioned in the Introduction, the basic domain/NLS of Tat contributes to the interaction of extracellular Tat with integrins (Urbinati et al., 2005a) and KDR (Albini et al., 1996b) that, in turn, trigger a complex signal transduction pathway that leads to proangiogenic activation of ECs (Urbinati et al., 2005a,b). On these bases, we investigated the possibility that, besides HSPGs, BSA-TatNLS binds also integrin $\alpha_{v} \beta_{3}$ and KDR, masking them to native Tat. We firstly evaluated the capacity of BSA-Tat-NLS to bind integrin $\alpha_{v} \beta_{3}$ by exploiting a SPR model that allows the study of the interaction of integrins with cognate ligands (Urbinati et al., 2005a). As shown in Fig. 4A, integrin $\alpha_{v} \beta_{3}$ binds surface-immobilized BSA-Tat-NLS. The binding is dose-dependent (Fig. 4B) and occurs with kinetic parameters (Table 3 ) that are comparable to those already calculated for the interaction of integrin $\alpha_{v} \beta_{3}$ with GSTTat (Urbinati et al., 2005a). In the same experimental conditions, the binding of the integrin to surface-immobilized BSA (here used as a negative control) is significantly lower (Fig. 4A) and is not dose-dependent (data not shown).

BSA-Tat-NLS binds also to surface-immobilized KDR (Fig. 4C). The interaction is specific since the other BSA conjugates tested do not bind to KDR (Fig. 4C). The binding is dose-dependent (Fig. 4D) and occurs with an affinity that is significantly lower in respect to that calculated for Tat/KDR interaction (Table 3 ).

Given the ability of BSA-Tat-NLS to bind to both integrin $\alpha_{v} \beta_{3}$ and KDR, we investigated its capacity to inhibit the biological consequences of the interaction of Tat with these two receptors. Once released by HIV+ cells, Tat accumulates in the extracellular matrix (Chang et al., 1997), where it promotes EC adhesion in a $\alpha_{v} \beta_{3}-$ dependent way (Urbinati et al., 2005a,b). We then evaluated the capacity of BSA-Tat-NLS to inhibit EC adhesion to plastic-coated Tat. As shown in Fig. 5A, BSA-Tat-NLS inhibits EC adhesion to plasticimmobilized Tat. The inhibition is specific since the other BSA conjugates tested are ineffective on Tat and BSA-Tat-NLS is ineffective on the EC adhesion to FN, a $\alpha_{5} \beta_{1}$-ligand here used as a negative control (Fig. 5A). Also, the inhibition is dose-dependent, occurring with an $\mathrm{ID}_{50}$ equal to $20 \mathrm{nM}$, a value that is close to the $K_{\mathrm{d}}$ calculated for the interaction of integrin $\alpha_{v} \beta_{3}$ with both BSA-Tat-NLS and intact Tat (Table 3). The HSPG-antagonist heparin, successfully used to inhibit HSPG-dependent lymphoid cell adhesion to Tat (Urbinati et al., 2009), does not affect EC adhesion to the transactivating factor (Fig. 5A). Taken together, these data indicate that BSA-Tat-NLS inhibits EC adhesion to Tat mainly by binding to integrin $\alpha_{\mathrm{v}} \beta_{3}$.

Integrin-dependent EC adhesion can be considered the first step of a process that, together with EC migration and proliferation, leads to neovascularization (Folkman and Klagsbrun, 1987). EC activation following a mechanical scratch of an EC monolayer resembles, at least in part, this process (Lauder et al., 1998). Tatadherent ECs are stimulated to repair a scratched monolayer, a biological activity often referred to as "motogenesis". In a preliminary set of experiments, we evaluated the contribution given by KDR, integrin $\alpha_{v} \beta_{3}$ and HSPGs to Tat-induced motogenesis. As shown in Fig. 5B, the KDR inhibitor SU5416 prevents the repair of the scratched area by Tat-adherent EC while the HSPGs-antagonist heparin exerts a very limited inhibition. The role of integrin $\alpha_{v} \beta_{3}$ in Tat-driven motogenesis was already demonstrated by using a peptidomimetic of the integrin recognition motif RGD present in Tat (Urbinati et al., 2005b). Taken together, these data suggest that Tat triggers motogenic activity in EC mainly by engaging KDR and $\alpha_{v} \beta_{3}$, with a marginal contribution given by HSPGs. On these bases we evaluated the effect of BSA-Tat-NLS on Tat motogenic activity. As shown in Fig. 5, BSA-Tat-NLS inhibits the repair of the scratched area by Tat-adherent EC. Although this inhibition is lower than that exerted by SU5416, it is specific since BSA-p53 shows a very limited inhibitory capacity.

In conclusion, BSA-Tat-NLS binds integrin $\alpha_{v} \beta_{3}$ and KDR, two receptors that, together with HSPGs, are implicated in the pro-angiogenic activation of ECs by Tat. Accordingly, besides LTR-transactivation, BSA-Tat-NLS inhibits also pro-angiogenic EC adhesion to Tat and Tat-driven motogenesis, suggesting its capacity to inhibit simultaneously different receptors and different pathological effects of Tat.

\section{Discussion}

Tat, the main transactivating factor of HIV-1, contributes to both AIDS progression and AIDS-associated pathologies, thus being considered a preferential target for the development of anti-AIDS therapies. Tat being originally discovered as the main transactivator of the viral genome, its inhibition has been initially approached by means of intracellular inhibitors (Giacca, 2004; Richter and Palù, 


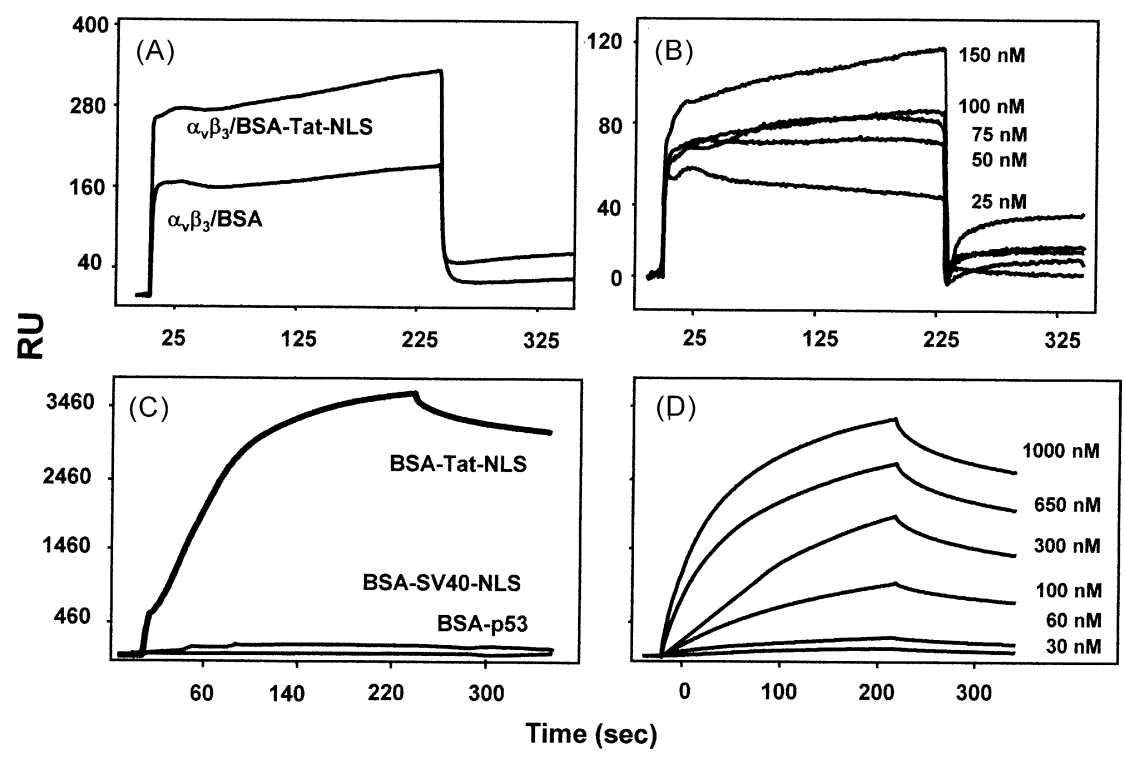

Fig. 4. BSA-Tat-NLS interaction with integrin $\alpha_{v} \beta_{3}$ and KDR.

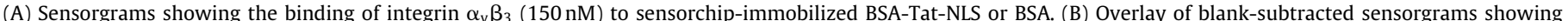

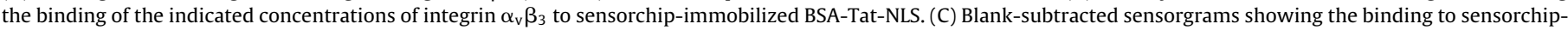

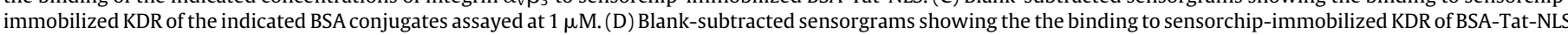
assayed at the indicated concentrations. The experiments shown are representative of several others that gave similar results.
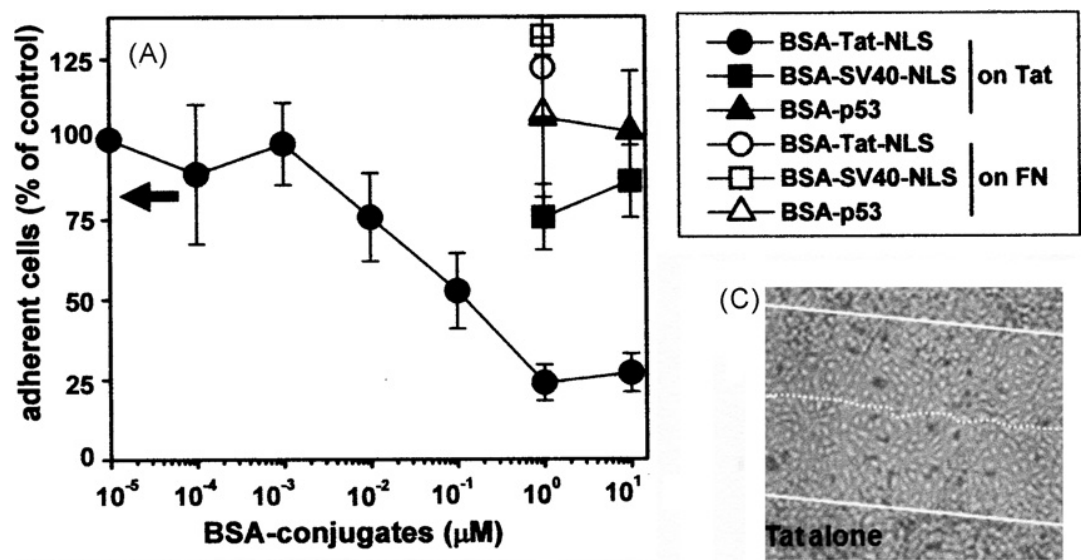

(C)
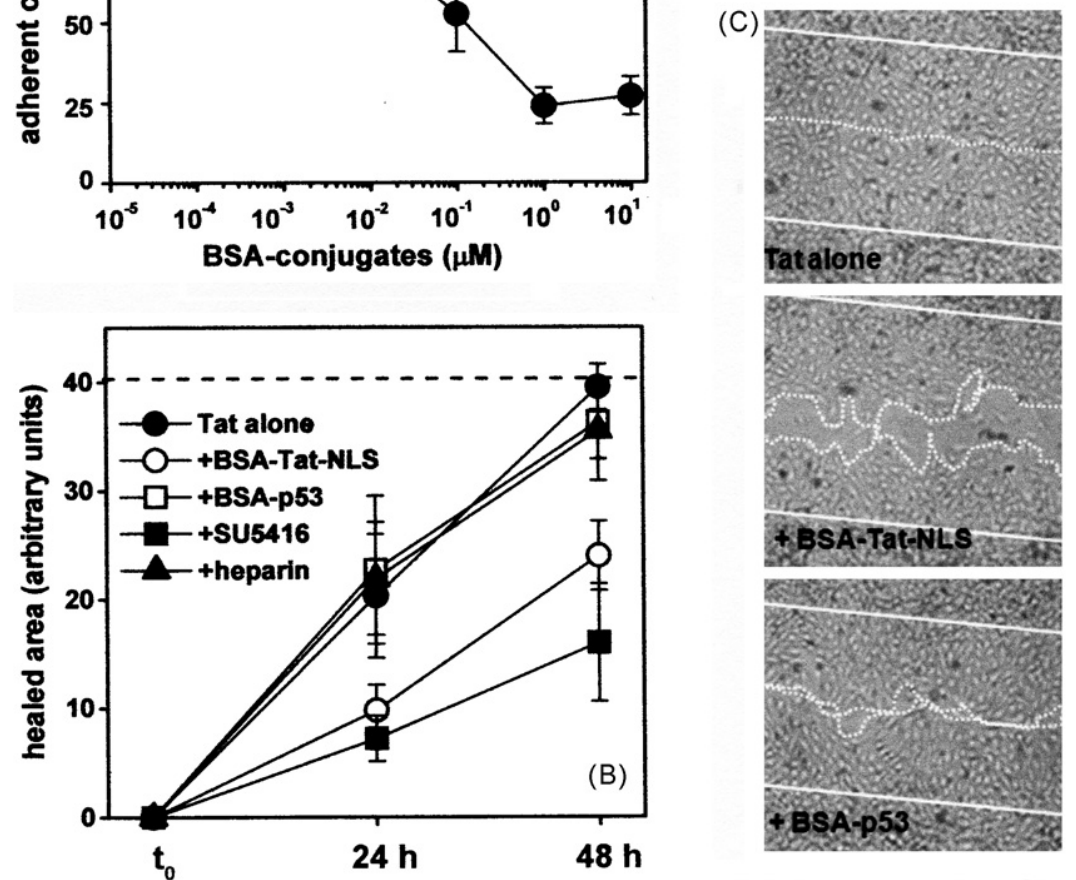

Fig. 5. Effect of BSA-Tat-NLS on $\alpha_{v} \beta_{3}$-dependent cell adhesion to Tat and on Tat-induced motogenesis.

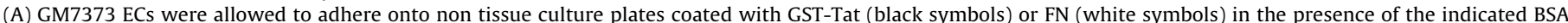

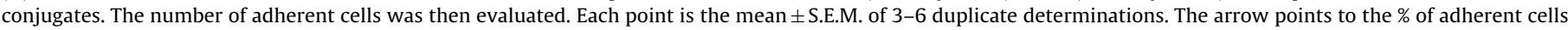

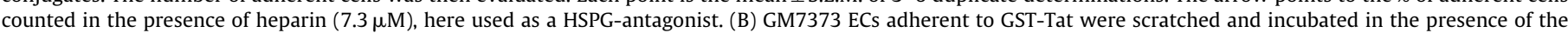

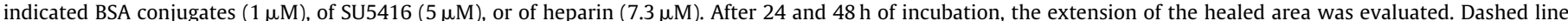

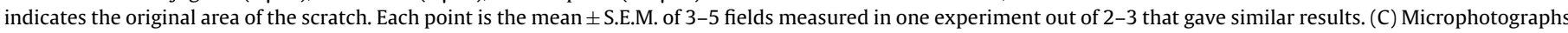

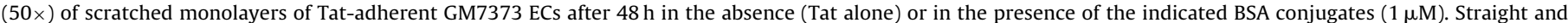
dotted lines mark the edge of the scratch at the beginning and at the end of the experiment, respectively. 
2006) aimed at the impairment of Tat nuclear translocation or of Tat/TAR interaction. More recently, when the biological relevance of extracellular Tat was assessed, a whole new set of extracellular inhibitors was developed (Rusnati and Presta, 2002b; Rusnati et al., 2005). However, none of these intra- or extracellular inhibitors turned out to act as efficient anti-AIDS drug. This is likely due to the fact that the design of Tat inhibitors faces multiple difficulties: i) since Tat acts both inside and outside the cell, an intracellular inhibitor would be ineffective extracellularly and vice versa; ii) since Tat interacts with different receptors, an inhibitor specifically directed at a selected interaction would be ineffective on the others. It follows that a multitargeted antagonist (able to inhibit Tat inside and outside the cell and/or to block simultaneously the various Tat receptors) would benefit in terms of efficiency, being able to interfere at once with different steps of Tat biology. In this scenario, the basic domain/NLS of Tat emerges as a preferential molecular target, being involved in several intra- and extracellular actions of Tat. In effect, the basic domain of Tat has been exploited to develop polyanionic compounds, mainly studied for their potential as extracellular Tat-antagonists (Rusnati and Presta, 2002b; Rusnati et al., 2005) or microbicides (Rusnati and Urbinati, 2009; Rusnati et al., 2009). Unfortunately, these compounds usually lack specificity and cell permeability and suffer from high toxicity and anticoagulant activity (Urbinati et al., 2008).

Alternative to the design of Tat-binding polyanions is the development of Tat mimetics able to bind and mask Tat receptors, an approach that has been long neglected, likely because Tat binds several distinct cell-surface receptors. Two exceptions are NeoR, a synthetic compound containing a hexa-arginine that binds CXCR4 and hampers its interaction with Tat (Hamy et al., 2000), and GCP64222 (Daelemans et al., 2000), a Tat peptoid that binds CXCR4 and inhibits HIV entry. Interestingly, both the compounds are also able to act intracellularly, disrupting the Tat/TAR complex (Hamy et al., 1997, 2000).

Taken together, these considerations point to peptides based on the structure of Tat basic domain/NLS as promising molecules for the design of intra- and/or extracellular inhibitors of Tat. However, the therapeutical exploitation of synthetic peptides is greatly limited by the fact that their binding to natural targets occurs with affinities ( $K_{\mathrm{d}}$ in the $\mathrm{mM}-\mu \mathrm{M}$ range) that are very low if compared to those of parent proteins $\left(K_{d}\right.$ in the pM-nM range) (Goldfarb et al., 1986). This limit has been succesfully overcome by conjugating multiple copies of peptides to larger proteins (Goldfarb et al., 1986). Accordingly, we found that a single peptide representing the basic domain/NLS of Tat does not inhibit HSPG-dependent Tat-transactivation in HL3T1 cells (Fig. 1A), although it retains its capacity to bind to heparin/HSPGs (Rusnati et al., 1998). In contrast, when conjugated to BSA in multiple copies (up to four) (Friedler et al., 1999), Tat-NLS acquires Tat-antagonist potential. In agreement with these data, we never succeeded in saturate cell-surface HSPGs with different basic peptides including Tat-NLS (data not shown), while BSA-Tat-NLS saturates HL3T1 cell surface at concentrations that are close to that of Tat ( 5 and $8 \mathrm{nM}$, respectively, see Fig. 2). Also, BSA-Tat-NLS binds heparin with an affinity that is comparable to that of intact Tat (Table 2).

BSA-SV40-NLS and its reversed counterpart do not bind to heparin despite their high positive charge. As a consequence, BSASV40-NLS does not bind to cell surface HSPGs and does not inhibit Tat internalization and transactivating activity, demonstrating that a mere positive charge is not sufficient to basic peptides to bind to heparin/HSPGs (Mulloy and Linhardt, 2001) and to exert Tatantagonist activity and pointing to the specificity of the inhibitory capacity of BSA-Tat-NLS.

As mentioned in introduction, the basic domain of Tat/NLS mediates Tat nuclear translocation and interaction with TAR RNA, suggesting that derivatives of the Tat basic domain/NLS may inter- fere with these two intracellular events. Although we cannot rule out this possibility, in our experimental conditions BSATat-NLS proved unable to inhibit Tat at an intracellular level. Relevant to this point, however, is the observation that inhibition of nuclear translocation of transactivating factors turned out to be an inefficient strategy, since only a small amount of protein is enough for efficient transcriptional activity (Fulcher and Jans, 2003).

At an extracellular level, conjugation in multiple copies to BSA confers to the Tat basic domain/NLS peculiar features that make it an interesting compound for the design of efficient and versatile Tat-antagonists:

i) due to its capacity to bind and mask HSPGs, BSA-Tat-NLS "desensitizes" cells when administered in the absence of Tat. Differently, classical extracellular Tat-binding inhibitors (like polyanionic compounds) can only sequester the transactivating factor in the extracellular environment, exerting no effect on the cells themselves;

ii) besides HSPGs, BSA-Tat-NLS binds also integrin $\alpha_{v} \beta_{3}$ with an affinity that is even higher than that of intact Tat (Table 3). As a consequence, BSA-Tat-NLS inhibits EC adhesion to substrateimmobilized Tat. BSA-Tat-NLS shares this capacity with other classical integrin-antagonist such as RGD-containing peptides. However, while the latters prevent integrin-dependent EC adhesion to different adhesive proteins (Rusnati et al., 1997b), BSA-Tat-NLS inhibits only EC adhesion to Tat, leaving unaffected that to FN.

iii) BSA-Tat-NLS interacts also with KDR. Actually, the affinity of this interaction is significantly lower than that of KDR with intact Tat (Table 3). This is possibly due to the fact that Tat/KDR interaction, in contrast with those with HSPGs and integrins, occurs with a very high affinity (in the pM range), implying a very intimate interaction that may be scarcely reproducible with linear peptides, also if presented in multimeric form. Despite its relatively low affinity for KDR, BSA-Tat-NLS succeeds in inhibiting Tat-induced motogenesis, that depends, at least in part, on KDR/Tat interaction.

Tat binds also chemokine receptors CXCR4 and CCR5 (Albini et al., 1998). Although the basic domain of Tat does not seem to mediate these interactions, a synthetic compound containing a hexa-arginine binds CXCR4 hampering its interaction with Tat (Hamy et al., 2000) and suggesting that also BSA-Tat-NLS (or its derivatives) may inhibit this interaction.

The use of BSA-Tat-NLS may be envisaged in contexts other than Tat inhibition:

i) always in the field of AIDS, an intricate network of interactions exists among HSPGs, Tat, gp120 and HIV itself: besides Tat, HSPGs bind gp120 through a basic domain called "variable loop 3" (Ping et al., 1999). As a consequence, HSPGs act as receptor for HIV, promoting its adsorption to the surface of target cells (Bobardt et al., 2004). On the other hand, Tat tethered to cellsurface HSPGs binds gp120, enhancing virus attachment and entry into the cell (Marchiò et al., 2005). In this complex scenario, BSA-Tat-NLS may block HIV infection by disrupting the direct interaction of gp120 with HSPGs and/or by preventing the formation of the ternary complex HSPGs/Tat/gp120 at the cell surface.

ii) in the field of angiogenesis, HSPGs are known to regulate the process of neovascularization modulating ligand interaction and activation of both KDR and integrins (Woods et al., 1998; Neufeld et al., 1999). Altough in our hands HSPGs seem to play a marginal role in the motogenic capacity of Tat (Fig. 5), the capacity of BSATat-NLS to bind and interfere with HSPGs, KDR and integrins may 
be exploited to design anti-angiogenic drugs aimed at disrupting the intimate "cross talk" existing among these three receptors.

Additional experiments are required to investigate all these possibilities, with particular attention focused on possible toxic or immunogenic effects exerted by BSA-Tat-NLS or its derivatives and their possible agonist effects on signaling receptors such as KDR and integrins.

\subsection{Conclusions}

In conclusion, once conjugated to BSA in multiple copies (up to four), peptides representing the Tat basic domain/NLS interfere with Tat biology at different levels, thus representing promising molecules for the design and development of new dendrimeric compounds to be employed as multitargeted drugs for the treatment of AIDS and AIDS-associated pathologies.

\section{Acknowledgments}

This work was supported by grants from CARIPLO foundation, $60 \%$ and ISS (AIDS Project) to M.R. and from the Israel Science Foundation, Israel Ministry of Health (grant no. 888/05) to A.L. We wish to thank Prof. M. Presta for helpful discussion and Dr. C. Urbinati and Mrs. E. Grillo for their helpful technical assistance.

\section{References}

Albini, A., Benelli, R., Presta, M., Rusnati, M., Ziche, M., Rubartelli, A., Paglialunga, G., Bussolino, F., Noonan, D., 1996a. HIV-tat protein is a heparin-binding angiogenic growth factor. Oncogene 12, 289-297.

Albini, A. Soldi, R., Giunciuglio, D. Giraudo, E. Benelli, R., Primo, L, Noonan, D., Salio, M., Camussi, G., Rockl, W., Bussolino, F., 1996b. The angiogenesis induced by HIV1 tat protein is mediated by the Flk-1/KDR receptor on vascular endothelial cells. Nat. Med. 2, 1371-1375.

Albini, A., Ferrini, S., Benelli, R., Sforzini, S., Giunciuglio, D., Aluigi, M.G., Proudfoot, A.E., Alouani, S., Wells, T.N., Mariani, G., Rabin, R.L., Farber, J.M., Noonan, D.M., 1998. HIV-1 Tat protein mimicry of chemokines. Proc. Natl. Acad. Sci. U.S.A. 95, 13153-13158.

Armon-Omer, A., Graessmann, A., Loyter, A., 2004. A synthetic peptide bearing the HIV-1 integrase 161-173 amino acid residues mediates active nuclear import and binding to importin alpha: characterization of a functional nuclear localization signal. J. Mol. Biol. 336, 1117-1128.

Bobardt, M.D., Salmon, P., Wang, L., Esko, J.D., Gabuzda, D., Fiala, M., Trono, D., Van der Schueren, B., David, G., Gallay, P.A., 2004. Contribution of proteoglycans to human immunodeficiency virus type 1 brain invasion. J. Virol. 78, 6567-6584.

Broder, Y.C., Stanhill, A., Zakai, N., Friedler, A., Gilon, C., Loyter, A., 1997. Translocation of NLS-BSA conjugates into nuclei of permeabilized mammalian cells can be supported by protoplast extract. An experimental system for studying plant cytosolic factors involved in nuclear import. FEBS Lett. 412, 535-539.

Chang, H.C., Samaniego, F., Nair, B.C., Buonaguro, L., Ensoli, B., 1997. HIV-1 Tat protein exits from cells via a leaderless secretory pathway and binds to extracellular matrix-associated heparan sulfate proteoglycans through its basic region. AIDS $11,1421-1431$.

Chauhan, A., Tikoo, A., Kapur, A.K., Singh, M., 2007. The taming of the cell penetrating domain of the HIV Tat: myths and realities. J. Control Release 117, 148-162.

Cullen, B.R., 1995. Regulation of HIV gene expression. AIDS 9 (Suppl. A), S19-32.

Daelemans, D., Schols, D., Witvrouw, M., Pannecouque, C., Hatse, S., van Dooren, S., Hamy, F., Klimkait, T., De Clercq, E., Vandamme, A.M., 2000. A second target for the peptoid Tat/transactivation response element inhibitor CGP64222: inhibition of human immunodeficiency virus replication by blocking CXC-chemokine receptor 4-mediated virus entry. Mol. Pharmacol. 57, 116-124.

Dayton, A.I., Sodroski, J.G., Rosen, C.A., Goh, W.C., Haseltine, W.A., 1986. The transactivator gene of the human $T$ cell lymphotropic virus type III is required for replication. Cell 44, 941-947.

Efthymiadis, A., Briggs, L.J., Jans, D.A., 1998. The HIV-1 Tat nuclear localization sequence confers novel nuclear import properties. J. Biol. Chem. 273, 1623-1628.

Ensoli, B., Buonaguro, L., Barillari, G., Fiorelli, V., Gendelman, R., Morgan, R.A., Wingfield, P., Gallo, R.C., 1993. Release, uptake, and effects of extracellular human immunodeficiency virus type 1 Tat protein on cell growth and viral transactivation. J. Virol. 67, 277-287.

Fisher, A.G., Feinberg, M.B., Josephs, S.F., Harper, M.E., Marselle, L.M., Reyes, G., Gonda, M.A., Aldovini, A., Debouk, C., Gallo, R.C., Wong-Staal, F., 1986. The transactivator gene of HTLV-III is essential for virus replication. Nature 320, 367-371.

Fittipaldi, A., Giacca, M., 2005. Transcellular protein transduction using the Tat protein of HIV-1. Adv. Drug Deliv. Rev. 57, 597-608.

Folkman, J., Klagsbrun, M., 1987. Angiogenic factors. Science 235, 442-447.
Frankel, A.D., Pabo, C.O., 1988. Cellular uptake of the tat protein from human immunodeficiency virus. Cell 55, 1189-1193.

Friedler, A., Zakai, N., Karni, O., Friedler, D., Gilon, C., Loyter, A., 1999. Identification of a nuclear transport inhibitory signal (NTIS) in the basic domain of HIV-1 Vif protein. J. Mol. Biol. 289, 431-437.

Fulcher, A.J., Jans, D.A., 2003. The HIV-1 Tat transactivator protein: a therapeutic target? IUBMB Life 55, 669-680.

Futaki, S., Suzuki, T., Ohashi, W., Yagami, T., Tanaka, S., Ueda, K., Sugiura, Y., 2001. Arginine-rich peptides. An abundant source of membrane-permeable peptides having potential as carriers for intracellular protein delivery. J. Biol. Chem. 276, 5836-5840.

Gautier, V.W., Sheehy, N., Duffy, M., Hashimoto, K., Hall, W.W., 2005. Direct interaction of the human I-mfa domain-containing protein, HIC, with HIV-1 Tat results in cytoplasmic sequestration and control of Tat activity. Proc. Natl. Acad. Sci. U.S.A. 102, 16362-16367.

Giacca, M., 2004. The HIV-1 Tat protein: a multifaceted target for novel therapeutic opportunities. Curr. Drug Targets Immune Endocr. Metabol. Disord. 4, $277-$ 285.

Goldfarb, D.S., Gariépy, J., Schoolnik, G., Kornberg, R.D., 1986. Synthetic peptides as nuclear localization signals. Nature 322, 641-644.

Goldstein, G., 1996. HIV-1 Tat protein as a potential AIDS vaccine. Nat. Med. 2. 960-964.

Grinspan, J.B., Mueller, S.N., Levine, E.M., 1983. Bovine endothelial cells transformed in vitro by benzo(a)pyrene. J. Cell Physiol. 114, 328-338.

Hamy, F., Felder, E.R., Heizmann, G., Lazdins, J., Aboul-ela, F., Varani, G., Karn, J., Klimkait, T., 1997. An inhibitor of the Tat/TAR RNA interaction that effectively suppresses HIV-1 replication. Proc. Natl. Acad. Sci. U.S.A. 94, 3548-3553.

Hamy, F., Gelus, N., Zeller, M., Lazdins, J.L., Bailly, C., Klimkait, T., 2000. Blocking HIV replication by targeting Tat protein. Chem. Biol. 7, 669-676.

Hariton-Gazal, E., Rosenbluh, J., Graessmann, A., Gilon, C., Loyter, A., 2003. Direct translocation of histone molecules across cell membranes. J. Cell Sci. 116 4577-4586.

Hodel, M.R., Corbett, A.H., Hodel, A.E., 2001. Dissection of a nuclear localization signal. J. Biol. Chem. 276, 1317-1325.

Jans, D.A., Xiao, C.Y., Lam, M.H., 2000. Nuclear targeting signal recognition: a key control point in nuclear transport? Bioessays 22, 532-544.

Kim, C.M., Vogel, J., Jay, G., Rhim, J.S., 1992. The HIV tat gene transforms human keratinocytes. Oncogene 7, 1525-1529.

Krichevsky, A., Rusnati, M., Bugatti, A., Waigmann, E., Shohat, S., Loyter, A., 2005. The fd phage and a peptide derived from its $\mathrm{p} 8$ coat protein interact with the HIV-1 Tat-NLS and inhibit its biological functions. Antiviral Res. 66, 67-78.

Lauder, H., Frost, E.E., Hiley, C.R., Fan, T.P., 1998. Quantification of the repair process involved in the repair of a cell monolayer using an in vitro model of mechanical injury. Angiogenesis 2, 67-80.

Liang, S.H., Clarke, M.F., 2001. Regulation of p53 localization. Eur. J. Biochem. 268, 2779-2783.

Mann, D.A., Frankel, A.D., 1991. Endocytosis and targeting of exogenous HIV-1 Tat protein. EMBO J. 10, 1733-1739.

Marchiò, S., Alfano, M., Primo, L., Gramaglia, D., Butini, L., Gennero, L., De Vivo, E. Arap, W., Giacca, M., Pasqualini, R., Bussolino, F., 2005. Cell surface-associated Tat modulates HIV-1 infection and spreading through a specific interaction with gp120 viral envelope protein. Blood 105, 2802-2811.

Mulloy, B., Linhardt, R.J., 2001. Order out of complexity-protein structures that interact with heparin. Curr. Opin. Struct. Biol. 11, 623-628.

Neufeld, G., Cohen, T., Gengrinovitch, S., Poltorak, Z., 1999. Vascular endothelial growth factor (VEGF) and its receptors. FASEB J. 13, 9-22.

Peterlin, B.M., Adams, M., Alonso, A., Baur, A., Ghosh, S., Lu, X., Luo, X., 1993. Tat transactivator. In: Cullen, B.R. (Ed.), Human Retroviruses. Oxford University Press, Oxford, pp. 75-100.

Ping, L.H., Nelson, J.A., Hoffman, I.F., Schock, J., Lamers, S.L., Goodman, M., Vernazza P., Kazembe, P., Maida, M., Zimba, D., Goodenow, M.M., Eron Jr., J.J., Fiscus, S.A., Cohen, M.S., Swanstrom, R., 1999. Characterization of V3 sequence heterogeneity in subtype $C$ human immunodeficiency virus type 1 isolates from Malawi: underrepresentation of X4 variants. J. Virol. 73, 6271-6281.

Richter, S.N., Palù, G., 2006. Inhibitors of HIV-1 Tat-mediated transactivation. Curr. Med. Chem. 13, 1305-1315.

Rizzi, C., Alfano, M., Bugatti, A., Camozzi, M., Poli, G., Rusnati, M., 2004. Inhibition of intra- and extra-cellular Tat function and HIV expression by pertussis toxin B-oligomer. Eur. J. Immunol. 34, 530-536.

Rusnati, M., Presta, M., 2002a. HIV-1 Tat protein and endothelium: from protein/cell interaction to AIDS-associated pathologies. Angiogenesis 5, 141-151.

Rusnati, M., Presta, M., 2002b. HIV-1 Tat protein: a target for the development of anti-AIDS therapies. Drug Fut. 27, 481-493.

Rusnati, M., Urbinati, C., 2009. Polysulfated/sulfonated compounds for the development of drugs at the crossroad of viral infection and oncogenesis. Curr. Pharmacol. Des. 15, 2946-2957.

Rusnati, M., Coltrini, D., Oreste, P., Zoppetti, G., Albini, A., Noonan, D., d'Adda di Fagagna, F., Giacca, M., Presta, M., 1997a. Interaction of HIV-1 Tat protein with heparin. Role of the backbone structure, sulfation, and size. J. Biol. Chem. 272, 11313-11320.

Rusnati, M., Tanghetti, E., Dell'Era, P., Gualandris, A., Presta, M., 1997b alphavbeta3 integrin mediates the cell-adhesive capacity and biological activity of basic fibroblast growth factor (FGF-2) in cultured endothelial cells. Mol. Biol. Cell 8, 2449-2461.

Rusnati, M., Tulipano, G., Urbinati, C., Tanghetti, E., Giuliani, R., Giacca, M., Ciomei, M. Corallini, A., Presta, M., 1998. The basic domain in HIV-1 Tat protein as a target for 
polysulfonated heparin-mimicking extracellular Tat antagonists. J. Biol. Chem 273, 16027-16037.

Rusnati, M., Tulipano, G., Spillmann, D., Tanghetti, E., Oreste, P., Zoppetti, G., Giacca, M., Presta, M., 1999. Multiple interactions of HIV-I Tat protein with size-defined heparin oligosaccharides. J. Biol. Chem. 274, 28198-28205.

Rusnati, M., Taraboletti, G., Urbinati, C., Tulipano, G., Giuliani, R., Molinari-Tosatti, M.P., Sennino, B., Giacca, M., Tyagi, M., Albini, A., Noonan, D., Giavazzi, R., Presta, M., 2000. Thrombospondin-1/HIV-1 tat protein interaction: modulation of the biological activity of extracellular Tat. FASEB J. 14, 1917-1930.

Rusnati, M., Urbinati, C., Caputo, A., Possati, L., Lortat-Jacob, H., Giacca, M., Ribatti, D., Presta, M., 2001a. Pentosan polysulfate as an inhibitor of extracellular HIV-1 Tat. J. Biol. Chem. 276, 22420-22425.

Rusnati, M., Urbinati, C., Musulin, B., Ribatti, D., Albini, A., Noonan, D., Marchisone, C., Waltenberger, J., Presta, M., 2001b. Activation of endothelial cell mitogen activated protein kinase ERK(1/2) by extracellular HIV-1 Tat protein. Endothelium $8,65-74$.

Rusnati, M., Oreste, P., Zoppetti, G., Presta, M., 2005. Biotechnological engineering of heparin/heparan sulfate: a novel area of multi-target drug discovery. Curr. Pharmacol. Des. 11, 2489-2499.

Rusnati, M., Vicenzi, E., Donalisio, M., Oreste, P., Landolfo, S., Lembo, D., 2009. Sulfated K5 Escherichia coli polysaccharide derivatives: a novel class of candidate antiviral microbicides. Pharmacol. Ther. 123, 310-322.

Schwartz, S., Felber, B.K., Fenyö, E.M., Pavlakis, G.N., 1990. Env and Vpu proteins of human immunodeficiency virus type 1 are produced from multiple bicistronic mRNAs. J. Virol. 64, 5448-5456.
Tyagi, M., Rusnati, M., Presta, M., Giacca, M., 2001. Internalization of HIV-1 tat requires cell surface heparan sulfate proteoglycans. J. Biol. Chem. 276, 3254-3261.

Urbinati, C., Bugatti, A., Giacca, M., Schlaepfer, D., Presta, M., Rusnati, M., 2005a. alpha(v)beta3-integrin-dependent activation of focal adhesion kinase mediates NF-kappaB activation and motogenic activity by HIV-1 Tat in endothelial cells. J. Cell Sci. 118, 2958-3949.

Urbinati, C., Mitola, S., Tanghetti, E., Kumar, C., Waltenberger, J., Ribatti, D., Presta, M., Rusnati, M., 2005b. Integrin alphavbeta3 as a target for blocking HIV-1 Tatinduced endothelial cell activation in vitro and angiogenesis in vivo. Arterioscler. Thromb. Vasc. Biol. 25, 2315-2320.

Urbinati, C., Chiodelli, P., Rusnati, M., 2008. Polyanionic drugs and viral oncogenesis: a novel approach to control infection, tumor-associated inflammation and angiogenesis. Molecules 13, 2758-2785.

Urbinati, C., Nicoli, S., Giacca, M., David, G., Fiorentini, S., Caruso, A., Alfano, M., Cassetta, L., Presta, M., Rusnati, M., 2009. HIV-1 Tat and heparan sulfate proteoglycan interaction: a novel mechanism of lymphocyte adhesion and migration across the endothelium. Blood 114, 3335-3342.

Watson, K., Edwards, R.J., 1999. HIV-1-trans-activating (Tat) protein: both a target and a tool in therapeutic approaches. Biochem. Pharmacol. 58, 1521-1528.

Woods, A., Oh, E.S., Couchman, J.R., 1998. Syndecan proteoglycans and cell adhesion. Matrix Biol. 17, 477-483.

Wright, C.M., Felber, B.K., Paskalis, H., Pavlakis, G.N., 1986. Expression and characterization of the trans-activator of HTLV-III/LAV virus. Science 234, 988992. 